\title{
LAS CORTES Y LA VIDA LOCAL
}

LA Ley de 17 de julio, creadora de las Cortes, contiene virtualidades que, rebasando los moldes de ia organización política, confieren sentido al complejo de las instituciones que articulan la vida social.

Cortes del signo a que responde este comentario entrañan, en efecto, un significado decisivo para juzgar el conjunto institucional. La misma Ley que las crea tiene una peculiaridad que la di. ferencia radicalmente de las Leyes constitucionales u orgánicas mediante las que se crean los Parlamentos y se otorga el derecho electoral en las épocas liberales.

Las de esta última clase son leyes exclusivamente formales, de carácter procesal, ya que no se proponen sino tramitar un proceso de voluntad indiferente a todo contenido político, a toda noción de valor. Asambleas deliberantes designadas por el sufragio universal e igual de los individuos hacen sumamente fácil la labor del legislador que las establece. Tales leyes no pasan de la esfera de las determinaciones generales, en cuanto se limitan a señalar las con: diciones del electorado, a dividir el territorio en porciones equiva. lentes para la emisión del sufragio y a garantizar la libertad del voto. Se trata así de implantar una organización cuadriculada, sujeta a fácil calculabilidad y que posea la precisión de líneas de una figura regular diseñada en plano geométrico.

Las leyes que responden a criterios de representación funcio. nal $\mathrm{u}$ orgánica son leyes constructivas que contienen una normalización entrañada en la vida social concreta, e insertan de este modo las vigencias vitales en la órbita del interés político. Pertenecen al mundo de la actividad-psíquica y económica-, no inmovilizan en cuadros territoriales y calculados por Decreto el desarrollo de una figura en cierto modo inaprehensible y atienden menos al perfil que al carácter interno y vital.

Esta diversidad de sentido de las leyes que organizan la representación se relaciona con el concepto que de éstạ se posea. Si se 
estima que la representación electiva es el acto creador del Estado. y con él de toda la vida política, se establece el criterio de que las Asambleas asumen función constituyente y son, por lo mismo, depositarias natas de la soberanía. $Y$ paralelamente se coloca en lo inorgánico-los individuos-electores-el asiento de la vida organizada.

Pero si, por el contrario, la representación implica ya la existencia de una vida social organizada, las Asambleas carecen de función constituyente y de soberanía originaria. Extienden sus raíces por el sistema social para extraer jugos de vida y "participar" en el gobierno asistiendo a jerarquías naturales o a selecciones destacadas en el cumplimiento de una función, y que son-unas y otras-expresiones constantes del incontenible impulso vital y de los nexos que él determina. La idea de representación se asocia así fuertemente a la de superioridad nata, y el problema que suscita la organización de una Asamblea o de unas Cortes no estriba en otra cosa que en determinar la forma y la medida de una "participación".

Proclama inequívocamente la Ley de 17 de julio que la representación no es posible sino cuando existe la Comunidad nacional: son los "elementos constitutivos" de ésta los que, en función de asistencia al Poder, van a ser representados. 0 sea, que los elementos constitutivos de la Comunidad tienen una existencia propia y sustantiva, no son creados por un decreto subjetivo de la voluntad del Poder, no advienen a la vida en virtud de una Ley electoral ni son entidądes puramente jurídicas. Pertenecen al mundo del ser, tienen una realidad óntica. Por eso "participan" en la vida del Estado y son susceptibles de representación.

En una Ley electoral individualista, el acto electoral crea el inte. rés representado: la Ley crea al elector, con este carácter puramente abstracto: le confiere poder de elegir representante, y en este acto de creación jurídica agota su carácter el Poder electoral. Una organización electoral ad boc, divorciada del mundo de las cosas existenciales y de los intereses vitales, equivale a una disección, por. que opera sobre sectores de realidad que no están vitalizados por lo que hay de inseparable en la realidad misma; por lo que la define en función de un ambiente, de una tarea común, de una Historia conjunta, de una empresa indivisible. Cortados los empalmes del elector con todo lo que constituye el medio interno y el externo, la cabina electoral ofrece gran semejanza con la máquina neumática. Por eso decía Rousseau, con frase que tanto se ha divulgado, que el pueblo inglés no era libre más que en el momento de designar sus repre. 2 sentantes. Cuando la libertad no es un valor, sino un procedimiento 
electoral, carece de una misión permanente y se extingue al cumplir el trámite para el que ha sido creada. Cuando, por el contrario, se vincula la representación a un sistema de valores y de relaciones, la colaboración entre representantes y representados no se interrumpe, porque está asegurada por la subsistencia del interés común. El individuo no se define entonces por uno de sus aspectos-el de elector-, ni es considerado al través únicamente de la específica actividad electoral. Inmerso en el mundo de los nexos sociales, adquiere la prestancia inherente a su aptitud realizadora de valores y tiene que ser considerado como totalidad concreta.

Esta conjunción del hombre y de la tarea, del individuo y de la Comunidad, por medio de una representación que se define colaborandc, es el soporte filosófico de un análisis que permite descifrar: a), el carácter de las Cortes; b), la posición de las Cortes en la vida del Estado; c), las funciones de las Cortes.

a) Como queda indicado, las Cortes no son órgano de soberanía ni residencia del Poder constituyente. Por lo mismo, no son una realidad jurídica superpuesta a la realidad nacional, y que puede sustituir y suplantar a ésta mediante una suma de poderes que, como los del Parlamento inglés, sean capaces de todo menos de cambiar e! sexo a las personas. El carácter de las Cortes radica en que los elementos vivos, necesarios y permanentes de la Comunidad nacional colaboran en el proceso político y legislativo, es decir, integran la organización del Estado y cooperan a realizar sus funciones sobre el supuesto indeclinable de la unidad de régimen.

Los poderes de las Cortes son, al mismo tiempo, limitados e imprescindibles.

Son limitados porque no constituyen el Estado, sino que "parti. cipan" en las tareas de gobierno (art. $\left.1 .^{\circ}\right)$. Esta participación supone que el Estado-o cosa participada-existe objetivamente, como fundación institucional anterior a las Cortes. Pero, a la vez, las Cortes, como sujeto participante, entrañan una realidad cooperadora de la actividad del ser en cuyas funciones participan. El resultado es un proceso de colaboración. "Eficaz instrumento de colaboración" en "la suprema potestad de dictar normas jurídicas de carácter general", que sigue encomendada a la Jefatura del Estado. Dicho con términos del Preámbulo de la Ley.

$Y$ a la vez que eficaz instrumento de colaboración, son las Cor. tes "principio de autolimitación para una institución más sistemática del Poder", según el mismo Preámbulo.

Es muy interesante desentrañar este sentido que comporta la 
autolimitación del Poder con el propósito de instituirse en un sistema. E importa, en primer término, considerar que dicho procesc de inserción o de institución significa un tránsito hacia los tiempos normales, una vez salvados los más graves trances de una crisis, y abre el período de consolidación de un Régimen.

El propio Preámbulo razona este criterio y se muestra consciente de la exigencia de "encuadramiento del Orden nuevo en un siste ma institucional con claridad y rigor". Claridad y rigor inseparables de la Norma, como la Norma es inseparable de la seguridad que brota de todo orden jurídico. Este designio-que se cifra en "la creación de un Régimen jurídicc"-pertenece a tiempos normales: hay una afinidad, no meramente gramatical, entre "Normalidad" y "Norma". Y es siempre el Preámbulo el que expresa estos pensamientos con absoluta nitidez: "Azares de una anormalidad, que por evidente es ocioso explicar, han retrasado la realización de este designio."

Aquí es donde aparece el otro carácter que hemos atribuído a los poderes de las Cortes. Además de limitados, son imprescindibles. Realizan el supuesto no sólo del Poder instituído, sino del Poder institucionalizado, es decir, hecho él mismo institución y servicio, asu. miendo la función de integrar el Estado en la medida en que mediante su acción se crean y dinamizan nuevos centros de interés pú. blico. Esta idea-la de un interés "público"-es la que diferencia el Estado de cualquier otra organización de Poder: Poderes primitivos de tipo contractual (clientela o feudalismo), Poderes oligárqui. cos de tipo capitalista o económico.

Poco importa que el origen del poder de las Cortes dimane de una "autolimitación". Todo poder de voluntad consciente procede así, y el Poder político es cifra y compendio de Poderes conscientes. Esto es lo que satura de sentido humano la vida colectiva, lo que-sin necesidad de caer en el antropomorfismo-hace del Estado un poder psíquico, calcado en las necesidades espirituales y orientado hacia la realización de una empresa también espiritual. Está escrito que vencerse a sí mismo requiere más temple humano que el necesario para conquistar ciudades y reinos. Pero en la obra política, la autolimi. tación no implica tanto el propio vencimiento como el dominio de las circunstancias. Es una invitación a la asistencia y a la colaboración, y así las energías que colaboran hacen suyo el interés de go. bierno y adquieren una disciplina unitaria y consciente. Es un resultado que se logra por las vías del Poder instituído en una Sociedad organizada, la cual se integra en jerarquías y culmina en la 4 Unidad de Mando. Y que, lográndose así, no puede lograrse por la 
vía opuesta: la del Poder que, en vez de autolimitarse como una voluntad que posee el dominio de sí y de las cosas, es creado artifi. cialmente por el sufragio inorgánico y carece de medios de acción: por su origen y por el mismo carácter informe de la Sociedad en que se produce.

b) El carácter de las Cortes determina su posición en la vida del Estado. La determina el artículo $1 .^{\circ}$ al caracterizarlas como el "órgano superior" de participación del pueblo español en las tareas del Estado. Las Cortes son el extracto de las energías totales del pueblo español, el conducto por el cual éstas se integran en el Estado, saturándose éste, en contrapartida; de vitalidad y de realidad social.

Las Cortes, por su composición, integran en el Estado la organización del Partido-Consejeros nacionales de F. E. T. y de las J. O. N. S.-, la organización administrativa-Provincias y Municipios-, la organización económica-Sindicatos nacionales-y la organización de las profesiones intelectuales. Con este matiz en lo que se refiere a las últimas: las tareas puramente intelectuales-de Universidades y de Academias-tienen una representación nata: Rectores y Presidentes. Los Cuerpos profesionales organizados en Colegios-Abogados, Médicos, Farmacéuticos, Veterinarios y Arquitectos-tienen una representación designada por los respectivos Decanos y Presidentes. El Canciller de la Hispanidad y los Presidentes de los Altos Tribunales completan la representación corporativa con aportaciones directamente estatales. Destaca entre éstas la de los Ministros.

Resultan de este modo las Cortes órgano potenciado-órgano de órganos-, y como totalidad organizada son superiores a los elemen. tos que las constituyen, aisladamente considerados.

$\mathrm{Y}$, además de órganos integrados por órganos-representación corporativa-, las Cortes son residencia y exponente de méritos personales, ampliamente seleccionados en las diversas esferas en que puede destacar la superioridad: la eclesiástica, la militar, la administrativa o la social y, en resumen, en cualquier actividad que acredite la prestación "de relevantes servicios a España". La designación de estas personas por el Jefe del Estado completa el sentido de la selección, vinculando al mérito acreditado en el ejercicio de las funciones la estimación de la calidad. política y del criterio de confianza.

El número de Procuradores no es un númeroclausum, pero existen límites establecidos: $10^{\circ}$, por las normas reguladoras del Conse. 
jo Nacional, con la específica oscilación que determina el artículo 35 de los Estatutos de F. E. T. y de las J. O. N. S. ; $2 .^{\circ}$, por el cálculo, de los representantes de los Sindicatos Nacionales, en número que no podrá exceder a la tercera parte del total de los Procuradores (con lo cual queda estrictamente limitada la función de las fuerzas económicas en el organismo político, en congruencia con el criterio justo y conveniente, de la subordinación de la Economía a la Política); $3 .^{\circ}$, por la fijación de los dignatarios o jerarcas de libre designación del Jefe del Estado, "en número no superior a cincuenta". Todas las demás representaciones, que hemos mencionado-natas o designadas-, están tasadas en la Ley.

Finalmente, se deduce de la composición de las Cortes que este órgano no está constituído sino en parte por designaciones automáticas, según el principio funcional a que responde la Cámara italiana de Fascios y Corporaciones. La Ley determina que los Procuradores son natos o electivos (art. $2^{\circ}$ ). Y los electivos no proceden de abajo, sino que son designados desde arriba, por conducto jerárquico.

c) Las atribuciones de las Cortes no son meramente legislativas, siquiera constituyan éstas su misión principal (art. $1^{\circ}{ }^{\circ}$ ). Se refieren, según el artículo 10, a "actos o leyes" que tengan por objeto las materias que se enumeran. Si por una parte, las atribuciones legislativas aparecen enunciadas limitativamente, por otra la intervención de las Cortes rebasa la esfera legislativa y penetra en el contenido de la vida económica, de la vida sindical y de los actos administrativos. Y si por un lado examinan los proyectos de Ley que el Gobierno les somete, por otro no carecen del derecho de iniciativa, no ejercitada por el Pleno, sino por las Comisiones (art. 15). El Preámbulo menciona "la audiencia de aspiraciones" en el inventario de facultades de las Cortes.

Por primera vez aparece en la vida del Régimien una distinción clara entre las disposiciones legales y las administrativas. Ni ratione materia ni formalmente existía hasta ahora criterio inequívoco cie diferenciación. Recuérdese que una disposición de alcance constitucional, como el Fuero del Trabajo, fué promulgada por Decreto. $\mathbf{Y}$ desde el punto de vista formal, aunque los Decretos solían llevar la firma de los Ministros anexa a la del Jefe del Estado, no tenía justificación suficiente este carácter para diferenciarlos de las Leyes.

Ahora el carácter legal de una disposición será formal y materialmente identificable cuando se trate de las cuestiones enumera. das en el artículo 10, que determina la competencia del Pleno de las 
Cortes. Pero lo será también, a tenor del artículo 12, cuando se trate de disposiciones "que deban revestir forma de ley", bien porque así lo establezca alguna posterior a la que crea las Cortes, bien porque lo determine una Comisión de legistas y de políticos que pertenecen a las mismas Cortes. Con lo cual éstas fijan las própias materias de su colaboración.

Se completa esta competencia y se afirma el sentido formal de la ley al través de la prescripción del artículo 13, que regula las Ordenanzas de urgencia, de tal suerte que el Decreto-Ley que las exprese ha de ser sometido a las Cortes "acto continuo de la promulgación".

Y aun cuando continúa vinculada "en la Jefatura del Estado la suprema potestad de dictar normas jurídicas de carácter general" (Preámbulo), la misión de las Cortes es preceptiva en cuanto a la necesidad de intervenir en determinadas materias, y su carácter consultivo, en cuanto a la forma de esta intervención, adquiere tinte y vigor deliberante al conferir a las Leyes plenitud de sentido y supremo rango normativo. A là luz de este criterio ha de interpretarse el artículo 17, que diseña la figura del veto del Jefe del Estado. Indudable veto absoluto-facultad interceptora de la Ley-, pero explícito reconocimiento de que la Ley requiere la colaboración de las Cortes.

Para el comentario en una Revista de la índole de la nuestra, nada es más interesante que destacar el rango que los órganos de la Vida local asumen en la Ley.

Obsérvese, en primer término, que la representación territorial en las Cortes halla la totalidad de su desenvolvimiento en el núcleo municipal y en el provincial, así diseñados en el apartado e) del artículo 2.": "Los Alcaldes de las cincuenta capitales de provincia, los de Ceuta y Melilla, y un representante por los diemás Municipios de cada Provincia, designado a través de la Diputación respectiva."

Las consideraciones que sugiere este apartado cabe sintetizarlas así:

a) Reconocimiento de la realidad orgánica de la vida local: mediante su incorporación plena a la vida política y su participación en las funciones del Poder.

b) Consiguiente transformación de los órganos locales de carácter administrativo en órganos de carácter político y en factores de decisiones legislativas de interés general. 
c) Consagración de la vigente división provincial, que ha logrado arraigo al través de una existencia más que secular, y que se mantiene en su doble acepción de cuadro agrupador de Municipios y de división territorial que responde a un número fijo de provincias, sólo acrecentado ahora con la mención de las ciudades de Ceuta y Melilla, en la que parece apuntar el brote de una nueva provincia: la africana.

d) Concepto de la Provincia como determinación de las rela: ciones de carácter intermunicipal o como cuadro de organización, en efecto, de Municipios de diverso volumen-grandes y pequeños-, entre los que destaca el interés de la capital que señala el relieve jerárquico provincial.

e) Distinción entre los Municipios que son capital de Provincia y los que no lo son, con la respectiva atribución de un carácter representativo: la representación de los primeros es única y nata $\mathbf{y}$ encarna en el Alcalde; la de los restantes es conjunta y designada en acto electivo-cuya regulación habrá de ser establecida-de carácter jerárquico: realizado por la Diputación Provincial.

f) : Carácter igualitario de la representación provincial, como corresponde al concepto de la personalidad territorial, que es independiente de la extensión y de la población y está caracterizada por el valor que como "núcleo" político-administrativo posee.

De esta suerte los intereses locales asumen una función representativa o cooperadora del interés general, y dejan de ser expre. sión del interés exclusivo de localidad. Significan la organización del territorio con alcance político, con finalidad que interesa al propio Estado o que forma parte de las realizaciones de éste.

El tema es muy amplio, y aquí no vamos a desflorarlo. Se trata nada menos que de determinar el carácter de la vida local en el Estado totalitario, en el Estado moderno. Sólo cuando no se depura la técnica, inseparable del rigor de los conceptos, pueden intercambiarse frívolamente estas expresiones: Estado totalitario, Estado corporativo. Del hecho de que el Estado, precisamente por abarcar todas las manifestaciones de la vida, se integra con las Corporaciones, y no sólo con los individuos, deduce una mente sumaria que el Estado corporativo es la etiqueta que conviene al Estado total. Pero una cosa es el Estado que se asimila las Corporaciones y otra muy distinta el Estado formado por ellas. El primero domina las Corporaciones; el segundo está determinado por ellas, 
fuera de las cuales carece de realidad jurídica. El Estado fascista es corporativo en la primera acepción, precisada así por Prélot, con palabras que cita Costamagna: "El Estado fascista no se define Estado corporativo porque esté construído corporativamente. Se afirma en cuanto él es por sí mismo la Corporación" (1).

Es el problema mismo del interés general o del "Bien común", irreducible a toda noción aritmética o cuantitativa, precisamente porque es un valor o noción cualitativa. Y si el interés general encarna en el Estado, el Estado no es una agregación de dimensiones o una suma de bienes particulares. Es la representación de un bien en sí, de naturaleza espiritual y de compleja formación, pero que significa todo lo contrario que una fusión de egoísmos: la superación de los intereses aislados y específicos de individuos, de clases y de corporaciones.

Para superarlos necesita imprescindiblemente asimilárselos. No puede desconocerlos, cerrando los ojos ante la espléndida diversidad. Los domina en la medida en que se nutre con ellos, convirtién. dolos en su propia sustancia. El Estado totalitario es el Estado-Sociedad o el Estado integración. A diferencia del Estado estamental, tiene vida propia y no vive de prestado. A diferencia del Estado liberal, no es un soberano abstracto cuya subsistencia jurídica se vincula a su capacidad inhibitoria frente a la organización de la vida real. Ni mero lazo político como el Estado de Corporaciones, ni mera estructura jurídica como el Estado liberal, sino Poder asimilador de relaciones sociales y que posee capacidad para transformarlas mientras las conduce en una dirección nueva-la del inte. rés general-y las traba en nuevas conexiones de sentido.

(1) Indudablemente no es éste el sentido que la literatura-y no exclusi vamente la periodística-y la práctica sobre todo han dado a la frase "Estado corporativo". La organización corporativa, al ser oficializada, ha recibido singular consagración y un relieve jurídico insospechado. No hay para qué aludir ahora a discusiones de escuela acerca del carácter juríaico de los Sindicatos y de las Corporaciones: ¿Poseen personalidad jurídica? ¿Son organos del Estado? ¿Qué significa la figura de Corporación de Derecho público? ¿Qué valor tiene el Sindicato vertical como "instrumento al servicio del Estado" en los términos en que lo define nuestro Fuero del Trabajo?

Cualquiera que sea la posición jurídica de la Organización corporativa, entraña la afirmación deP carácter público de los intereses que representa. Y se ha creado así el espejismo del "Estado corporativo", significando la alusión expresa al fenómeno corporativista en cuanto se manifiesta en la estructura estatal. La doctrina del Estado-Corporación a que se refiere Prélot fué construida también, con otro alcance, bajo el signo liberal y aparece ligada a la doctrina de la personalidad y de los derechos públicos subjetivos.

Quede formulada esta salvedad, que interesa a la tradición terminologica. Por lo demás, es muy cierto que el "Estado corporativo" moderno, a diferencia del medieval, no es producto de las Corporaciones, sino dominador de ellas. 
Esta aptitud que el Estado despliega, y que no es tan solo disciplinaria, sino creadora de vida nueva, se manifiesta en ese mundo de fenómenos sociales de especial naturaleza que se suscita en el cruce de los elementos territoriales con los personales y que determina una forma de vida-la local-y unas instituciones-las del gobierno de esos núcleos locales.

A diferencia de cualesquiera otros intereses corporativos, los de la vida local son territoriales. Corporación territorial-paradigma de las de esta clase-es el Estado, y ese carácter territorial da a las Corporaciones locales rango político, aunque sea al propio tiempo origen de un peligro político también: el de la secesión. Porque, en efecto, la integración, como la desintegración política, opera precisamente sobre bases territoriales: se extiende o se contrae el gobierno sobre las personas en simultaneidad con el crecimiento o la restricción del área territorial. $\mathrm{Y}$ es el territorio el escenario de toda vida política, pero sobre todo-es lo más interesante y lo que aquí importa anotar-es la base imprescindible de formación, de generalización y de representación del interés general.

El Derecho se unifica al través de su territorialización, y el tránsito de las leyes personales a las leyes de carácter territorial acompaña a la creación de las Naciones y marca el itinerario a los conceptos jurídicos, como el de Estado y el de soberanía. El concepto de "residente", a diferencia del de "agremiado", es exclusivamente territorial, pero su realidad jurídica es decisiva para comprender el Estado, y ya no resulta posible suplantarla ni desconocerla por mucho que se explore en la dirección corporativa o que se avance en la - organización de los intereses. Del mismo modo que no será ya posible que los Censos profesionales sustituyan al Censo administrativo.

$\mathrm{Y}$ ese concepto de "residente" sobre un territorio se ha elaborado $\mathrm{y}$ ha hecho sus primeras experiencias en los núcleos de vida local. Desde su origen están caracterizados por la relación de vecindad, y esta nota continuará dándoles vida. Quienes discuten acerca de si el Municipio es entidad natural o puramente legal, no deben perder de vista este criterio de la vecindad, como primera estructura del núcleo territorial, tan pronto com.o se rebasa el círculo familiar, que es independiente del territorio. Vecino (de vicus, barrio, lugar o aldea) es el próximo con quien inmediatamente se convive en un núcleo determinado por esta relación inmediata de vida común sobre un territorio fijo. El Derecho perfila después el carácter, distin10 guiendo la condición del "residente" y la del "transeúnte", según la 
naturaleza-duradera o efímera-de la relación entre la persona y el territorio. Se adquiere residencia o se "gana" vecindad según la adhesión que se muestra al territorio en un tracto de tiempo legal.

Tal carácter de territorialidad será la divisa de toda organización política: la del Municipio como la del Estado. Será también lo que otorgue fisonomía a la representación política. Será, por último, lo que sirva de soporte a la condición de "nacional" y permita que este interés unitario de la Nación o del Estado prevalezca sobre todo interés de sector y exprese la existencia de la Comunidad (1).

La historia de la representación ilustra estè proceso. Ella nos enseña que el territorio ha sido la base de una fusión de intereses que ha superado la antigua división estamental o clasista. Cierto que el origen de la representación de Ciudades o Villas entraña la idea de un privilegio-Ciudades con voto en Cortes-, pero toda libertad comienza por ser un privilegio. Lo interesante es observar que ese privilegio ya no es un privilegio de clase, sencillamente porque las Ciudades no son organizaciones clasistas, sino núcleos territoriales. Es un privilegio otorgado a una comunidad territorial por el Rey, representante de la unidad del Estado. Lo poseen las Ciudades: de realengo, y no las de señorío, que conservan la huella del privilegio de clase. Es, de esta suerte, un privilegio que se asocia a la exigencia de una incorporación, incorporación inseparable del pro. ceso formativo del Estado mismo. La protección del Rey crea un orden más duradero y más general que la protección del Señor, y ésta llega a ser innecesaria. Pero en este orden general radica el impulso que generaliza la representación y transforma en libertad el privilegio. Ello se ha logrado gracias a la unificación del territorio por un Poder central--el Rey, origen de 1 Estado-, fuente de un Dere-

(1) La Comunidad o Pueblo surge cuando, sobre una base territorial, se han unido los hombres en el Derecho comán. Esto es lo que impide identificar a) Pueblo con una clase: "cuydan algunos, quel Pueblo es llamado la gente menuda, assi como menestrales, e labradores; e esto non es ansí... Pueblo lla. man el ayuntamiento de todos los homes comunalmente, de los mayores, e de los medianos, e de los menores. Ca todos son menester..." Esta conocida definición de las Partidas ( $I$, tit. $X$, Ley $1^{*}$ ) sigue al Preliminar de la misma Partida e igual título, que comienza asi: "Comunaleza deue el Rey auer a todos los del su Señorío, para amar, e honrrar, e guardar a cada vno. dellos, según quel es, o el seruicio que del recibe." Es la Ley 3.9 de la misma Partida la que señala las razones par las cuales debe el Rey amar a su Pueblo y las especifica en relación con cada ofício, cuidando de destacar que es señalada obra de los Reyes hacer Justicia y Derecho. La Ley $1 .{ }^{*}$ del titulo XI establece la relación que existe entre el Pueblo y la tierra, cuyo señorío reivindica el Rey No se olvide que esta vinculación territorial a la Corona fue instrumento de lucha contra el feudalismo y medio de constituir el Pueblo sobre una base coman. 
cho general, en pugna-como la representación política ya maduracon toda idea de privilegio.

El ciclo representativo va a cerrarse. Ha evolucionado desde e: orden del privilegio personal o de clase al orden territorial en el cuadro de los Municipios. La última etapa corresponde a la representa. ción que no necesita entrenarse en la aristocracia del privilegio, ni necesita ser difundida con aliento de libertad igualitaria. Es la representación de orden jerárquico y funcional en el Estado que se integra con todas las actividades ordenadas de la vida social.

Esta ordenación representativa ha de asegurar el prevalecimiento del interés nacional. Lo logra mediante la ponderaciốn de los elementos representados y mediante la posición colaboradora, y no soberana, que confiere a esos elementos, a fin de que la decisión refleje el carácter unitario que es propio del superior interés público.

No es indiferente, por lo que respecta a la composición de las Cortes, que sean los intereses políticos, morales, intelectuales y territoriales los que prevalecen sobre los económicos y sindicales. La incorporación de los Municipios. agrupados en Provincias, significa que el interés local es también interés nacional, en consonancia con el doble carácter del Municipio: centro de vida diferenciada y circunscripción al través de la cual ejerce el Estado su competencia. La igualdad representativa de las capitales y la equiparación de los demás Municipios en el marco provincial muestra.la perfecta integración de estos órganos territoriales en el Estado.

Añádase a todo ello que las Corporaciones locales van a colaborar en la formación de su propio Estatuto, pues forman parte de unas Cortes cuya competencia comprende esta materia según una enunciación genérica y otra específica de la ley de 17 de julio: la primera, contenida en el apartado g) del artículo 10: "La ordenación político-jurídica de las Instituciones del Estado"; la segunda, en e! apartado h) : "Las Bases del Régimen local".

Puede considerarse como sintomático que, al ser proclamada la Ley creadora de las Cortes, se haya entregado a éstas, en el mismo acto, y exclusivamente, como caso sin plural, de momento, el Proyecto de Gobierno y Administración Local.

Ha de detenerse aquí el comentario de un texto. Esperemos la glosa, mucho más importante, de la vida. 